\title{
Editorial \\ Decline in breast cancer incidence due to removal of promoter: combination estrogen plus progestin
}

\section{Graham A Colditz}

Alvin J Siteman Cancer Center and Department of Surgery, Washington University School of Medicine, Campus Box 8100660 S Euclid Avenue, St Louis, MO 63110, USA

Corresponding author: Graham A Colditz, colditzg@wustl.edu

Published: 26 July 2007

This article is online at http://breast-cancer-research.com/content/9/4/108

Breast Cancer Research 2007, 9:108 (doi:10.1186/bcr1736)

(c) 2007 BioMed Central Ltd

See related research article by Jemal et al., http://breast-cancer-research.com/content/9/3/R28

\begin{abstract}
Combination estrogen plus progestin causes breast cancer. In light of this causal relation, the rapid decline in breast cancer incidence noted in 2003 , following an earlier and slower reduction in incidence from 1999, raises important issues regarding the proportion of this decline that may be due to a reduction in the use of combination therapy by postmenopausal women. The context of these national trends is reviewed and the strong link to the use of hormone therapy is discussed, after noting that screening cannot explain any substantial component of these trends. The rapid decrease in incidence, most evident among women aged 50 to 69 years and in estrogen receptor positive tumors, that parallels the decline in combination hormone use is consistent with a promoter effect for estrogen plus progestins.
\end{abstract}

A rigorous analysis of Surveillance, Epidemiology, and End Results (SEER) data [1], addressing trends on breast cancer incidence, tumor characteristics, and patterns of incidence for in situ cancer, added new insights into the impact that combination hormone therapy has on risk for breast cancer at the population level. Combination therapy (estrogen plus progestin [E\&P]) causes breast cancer and is classified as a carcinogen by the International Agency for Research on Cancer [2]. Here, I address how much of the recently reported decrease in incidence [1] is due to a reduction in the use of combination E\&P postmenopausal hormone therapy.

The association of unopposed estrogen with endometrial cancer provides strong evidence that hormone therapy can act as a late promoter of cancer. With the acknowledgment of the causal relation in the 1970s, a sharp decline in estrogen prescribing led to a parallel rapid decrease in incidence of endometrial cancer [3]. Uptake of E\&P therapy was somewhat slow, and epidemiologic data in the USA were limited in their ability to separate effects of combination therapy from those of unopposed estrogen. However, by 1995 prospective data indicated that E\&P therapy did not protect against breast cancer and that the increase in risk may be greater than for estrogen alone [4]. Although estrogen alone remained the treatment of choice for women without a uterus, between the mid-1970s and the mid-1980s surveillance data showed that the incidence of estrogen receptor positive tumors increased by an average of $131 \%$ in the population-based tumor registry of Kaiser Permanente in the USA (Portland, OR) [5], perhaps implicating the involvement of hormonal factors in the rising incidence of breast cancer.

Population-based epidemiologic studies [6] and cohort data [7] matured during the latter 1990s to show that combination E\&P therapy significantly increased risk, and that this was most evident among leaner women. Recommendations based on these findings were that women should avoid progestins if possible [8]. A broad range of epidemiologic studies continue to support the causal relation between combination E\&P and total breast cancer. Meanwhile, some investigators have focused on the increase in lobular cancer $[9,10]$; the clear estrogen receptor positive nature of these lobular tumors, as compared with ductal tumors, which are receptor positive to a lesser extent, provides a clearer indication that this subset of tumors is caused by combination E\&P. Studies of receptor positive tumors show that combination therapy clearly increases risk [5].

In 2002, the Women's Health Initiative (WHI) confirmed the epidemiologic findings relating combination hormone therapy to increased risk for breast cancer. Despite substantial non-

$\mathrm{E} \& \mathrm{P}=$ estrogen plus progestin; HER = Heart and Estrogen/Progestin Replacement Study; PAR = population attributable risk; SEER $=$ Surveillance, Epidemiology, and End Results; WHI = Women's Health Initiative. 
adherence to therapy, which exceeded $40 \%$ among women randomly assigned to E\&P, the predetermined stopping rules for the WHI led the independent data safety monitoring board to stop the trial early because of the adverse effect of therapy on breast cancer [11]. The intention to treat and, more importantly, the adherence-based relative risks (which approximate the relative risks from epidemiologic studies that record use and nonuse of therapy) were consistent with the Heart and Estrogen/Progestin Replacement Study (HERS) trial [12] and epidemiologic data showing an increase in risk in the initial 2 to 5 years of use. Furthermore, risk increased significantly with duration of therapy.

Based on data from the San Francisco mammography registry, prescribing of E\&P peaked in 1999. The use of hormone therapy was increasing at $1 \%$ per quarter before publication of the HERS report, but it declined by $1 \%$ per quarter after publication [13]. This decline in prescribing continued until the publication of the WHI in 2002, after which a more substantial decline of $18 \%$ per quarter was observed. The peak and decline through 1999 to 2002 is concordant with the HERS report in 1998 [12], which found a significant increase in coronary heart disease during the first year of therapy among women with prevalent coronary disease and, in addition, no long-term benefit in reducing coronary heart disease [14]. The growing epidemiologic evidence published since 2000 on the adverse effects of combination therapy on breast cancer added further support to avoid its use. Considering the prevalence of use of E\&P in California, Clarke and coworkers [15] estimated a population attributable risk (PAR, or the proportion of cases caused by E\&P) of up to $11 \%$, based on a prevalence of use of $30 \%$ and a relative risk of 1.4 . Given that substantially greater relative risks of 2 or higher have been reported [16], this estimated PAR may be conservative. Assuming a prevalence of use of $17.5 \%$ (the average reported for California in 2001 [15]), a relative risk of 1.49 gives a PAR of $7.9 \%$ and a relative risk of 2.0 gives a PAR of $14.9 \%$.

Evidence regarding breast cancer incidence rates now clearly shows a parallel drop in breast cancer consistent with the pattern of decreased prescribing. Jemal and coworkers [1] conducted a rigorous, state-of-the-art analysis using joint point analysis and drawing on SEER incidence data from 1975 through to 2003. They demonstrated a significant decrease in the incidence of invasive breast cancer from 1999 to 2003 in all 5-year age groups from 45 years and above, and a sharp decrease largely limited to estrogen receptor positive tumors in age groups from 50 to 69 between 2002 and 2003. Furthermore, although others have suggested that a $1 \%$ to $3 \%$ drop in screening mammography may account for this decline in incidence, Jemal and coworkers provided strong evidence against this contention. If screening were to account for a drop in incidence, then rates of in situ disease would also need to drop because they are almost only detected by mammography. Jemal and coworkers demonstrated that, before screening became widespread, in situ rates were low and rose with the uptake of screening to plateau from 1999 through to 2003. The lack of a drop in in situ cancer offers compelling evidence that a reduction in screening does not account for the drop in incidence of invasive breast cancer.

Others have analyzed SEER data over a shorter period [17] or draw on the unique resources of the California tumor registry and health maintenance organization datasets [18] to show similar relations between change in hormone therapy and a decrease in breast cancer incidence. Most recently, Robbins and Clarke [19] evaluated the change in prescribing, as estimated from the California Health Interview Survey, among almost three million non-Hispanic white women aged 45 to 74 years, and compared the findings with the change in breast cancer incidence across 58 counties in California. This thoughtful analysis shows that, from 2001 to 2004, the incidence of breast cancer declined by $8.8 \%$ in the counties with the smallest E\&P reductions, by $13.9 \%$ in those with intermediate reductions, and by $22.6 \%$ in counties with the greatest reductions in combination postmenopausal hormone therapy. Between 2001 and 2003, California Health Interview Survey data did not indicate any significant change in the proportion of women who reported having a mammogram during the previous 2 years, adding further evidence against this as a plausible major explanatory factor for the observed declines in breast cancer incidence. Even more evidence in support of this relation between decrease in E\&P prescribing and breast cancer comes from declines in incidence reported in New Zealand [20] and Germany [21] that parallel those in the USA.

Trends in obesity in the USA run counter to the decline in breast cancer incidence, the genetic make up of the population has not changed, and there has been a dramatic decline in breast cancer incidence in the USA that is largely confined to estrogen receptor positive tumors, along with similar declines documented in other countries. Given these findings, the evidence unarguably indicates that there is a causal relation between this abrupt reduction in use of E\&P hormone therapy and the decline in breast cancer. The public health impact of this must not be underestimated. In fact, this decrease, amounting to approximately 10,000 fewer cases, falls within the range of attributable risk estimates for beast cancer due to E\&P, suggesting that these estimates are conservative because not all women have ceased using combination therapy.

Although research issues remain, for instance regarding impact of dose of progestin per month on risk for breast cancer, women should be reassured that these data support a rapid risk reduction following cessation of therapy with E\&P. Long-term use may yet cause some residual increase in risk [22]. Finer analysis that accounts for duration of prior use may resolve this issue. 


\section{Competing interests}

The author declares that they have no competing interests.

\section{References}

1. Jemal A, Ward E, Thun MJ: Recent trends in breast cancer incidence rates by age and tumor characteristics among U.S. women. Breast Cancer Res 2007, 9:R28.

2. International Agency for Research on Cancer: Combined estrogen-progestogen postmenopausal therapy. In Combined Estrogen-progestogen Contraceptives and Combined Estrogenprogestogen Menopausal Therapy. Lyon: International Agency for Research on Cancer; 91:2007 [http://monographs.iarc.fr/ENG/ Meetings/91-menop-ther.pdf]

3. Austin DF, Roe KM: The decreasing incidence of endometrial cancer: public health implications. Am J Public Health 1982, 72:65-68.

4. Colditz GA, Hankinson SE, Hunter DJ, Willett WC, Manson JE, Stampfer MJ, Hennekens C, Rosner B, Speizer FE: The use of estrogens and progestins and the risk of breast cancer in postmenopausal women. N Engl J Med 1995, 332:1589-1593.

5. Glass AG, Hoover RN: Rising incidence of breast cancer: relationship to stage and receptor status. J Natl Cancer Inst 1990, 82:693-696.

6. Ross RK, Paganini-Hill A, Wan P, Pike M: Effect of hormone replacement therapy on breast cancer: estrogen versus estrogen plus progestin. J Natl Cancer Inst 2000, 92:328-332.

7. Schairer C, Lubin J, Troisi R, Sturgeon S, Brinton LA, Hoover R: Menopausal estrogen and estrogen-progestin replacement therapy and breast cancer risk. JAMA 2000, 283:485-491.

8. Willett WC, Colditz G, Stampfer M: Postmenopausal estrogens: opposed, unopposed, or none of the above. JAMA 2000, 283:534-535.

9. Li Cl, Weiss NS, Stanford JL, Daling JR: Hormone replacement therapy in relation to risk of lobular and ductal breast carcinoma in middle-aged women. Cancer 2000, 88:2570-2577.

10. $\mathrm{Li} \mathrm{Cl}$, Anderson BO, Daling JR, Moe RE: Trends in incidence rates of invasive lobular and ductal breast carcinoma. JAMA 2003, 289:1421-1424.

11. Rossouw JE, Anderson GL, Prentice RL, LaCroix AZ, Kooperberg C, Stefanick ML, Jackson RD, Beresford SA, Howard BV, Johnson $\mathrm{KC}$, et al:: Risks and benefits of estrogen plus progestin in healthy postmenopausal women: principal results From the Women's Health Initiative randomized controlled trial. JAMA 2002, 288:321-333.

12. Hulley S, Grady D, Bush T, Furberg C, Herrington D, Riggs B, Vittinghoff $E$ : Randomized trial of estrogen plus progestin for secondary prevention of coronary heart disease in postmenopausal women. Heart and Estrogen/progestin Replacement Study (HERS) Research Group. JAMA 1998, 280: 605-613.

13. Haas JS, Kaplan CP, Gerstenberger EP, Kerlikowske K: Changes in the use of postmenopausal hormone therapy after the publication of clinical trial results. Ann Intern Med 2004, 140:184-188.

14. Grady D, Herrington D, Bittner V, Blumenthal R, Davidson M, Hlatky M, Hsia J, Hulley S, Herd A, Khan S, et al.: Cardiovascular disease outcomes during 6.8 years of hormone therapy: Heart and Estrogen/progestin Replacement Study follow-up (HERS II). JAMA 2002, 288:49-57.

15. Clarke CA, Purdie DM, Glaser SL: Population attributable risk of breast cancer in white women associated with immediately modifiable risk factors. BMC Cancer 2006, 6:170.

16. Beral V: Breast cancer and hormone-replacement therapy in the Million Women Study. Lancet 2003, 362:419-427.

17. Ravdin PM, Cronin KA, Howlader N, Berg CD, Chlebowski RT, Feuer EJ, Edwards BK, Berry DA: The decrease in breastcancer incidence in 2003 in the United States. N Engl J Med 2007, 356:1670-1674.

18. Clarke CA, Glaser SL, Uratsu CS, Selby JV, Kushi LH, Herrinton $\mathrm{LJ}$ : Recent declines in hormone therapy utilization and breast cancer incidence: clinical and population-based evidence. $J$ Clin Oncol 2006, 24:e49-e50.

19. Robbins A, Clarke C: Regional changes in hormone therapy use and breast cancer incidence, California, 2001-2004. J Clin Oncol 2007 [Epub ahead of print].

20. Johnston M: Breast cancer drop linked to fall in use of HRT. New Zealand Herald 2006, 20 December [http://www.nzherald. co.nz/section/story.cfm?c_id=204\&objectid=10416198]
21. Katalinic A, Rawal R: Decline in breast cancer incidence after decrease in utilisation of hormone replacement therapy. Breast Cancer Res Treat 2007 [Epub ahead of print].

22. Chen WY, Hankinson SE, Rosner B, Colditz GA: Past use of hormone replacement therapy and breast cancer risk [abstract 10518]. J Clin Oncol 2007, Suppl:18S. 